in nitrogen status from those yielding effective strains. To some extent this can be explained by the fact that under field conditions the plant is not entirely dependent on the nodules for its nitrogen nutrition. In addition, as a result of multiple infection, in a particular area, the proportion of nodules produced by effective and ineffective strains may tend to be similar on all plants, resulting in fairly uniform vigour.

It may be of interest that some of the effectiveness tests were carried out during the winter months, the natural light then available being supplemented with artificial light from a battery of 'daylight' fluorescent tubes arranged as described by Low ${ }^{4}$. The intensity of the artificial light alone at plant-level $(12 \mathrm{~cm}$. below the fluorescent tubes) was approximately $300 \mathrm{ft}$. candles, the light being supplied for sixteen hours each day. Very satisfactory growth was obtained under these conditions, the dry weight attained by the plants being only slightly inferior to that of plants grown in summer.

I am indebted to Dr. G. Bond for his advice during the course of this investigation and to the Botany Department, University of Glasgow, for the use of the fluorescent lights.

Botany Department,

West of Scotland Agricultural College,

Glasgow. March 21.

1 Dunham, I. H., and Baldwin, J. L., Soil Sci., 32, 235 (1931). Chen H. K., J. Agric. Sci., 81, 479 (1941). Nicol, H., and Thornton, H. G., Proc. Roy. Soc., B, 130, 32 (1941). Virtanen, A. I., and Linkola, A. H., J. Microbiol. Serol., 12, 65 (1947). Burton, J. C. and Allen, O. N., Proc. Soil Sci. Soc. Amer., 14, 191 (1950).

${ }^{2}$ Purchase, H. F., and Vincent, J. M., Proc. Linn. Soc., N.S.W., 74, 227 (1949).

${ }^{3}$ Bond, G., and McGonagle, M., P., Ann. App. Biol. (in the press).

Low, A. J., Agriculture, 55, 210 (1948).

\section{Myxobacteria Mistaken for Nitrifying Bacteria}

THE nitrifying bacteria, like the sulphur microorganisms, have been studied almost entirely from a physiological aspect. With the exception of Nitrosomonas and Nitrobacter, the descriptions of the various genera have been copied from those given by the original investigators ${ }^{1}$. This has led to the description of nitrifying genera with the morphological characters of Myxobacteria, with which the cultures were, apparently, contaminated.

Although enrichment cultures similar to those originally devised by Winogradsky have been used by subsequent workers, only Nitrosomonas and Nitrobacter species have been isolated. The remaining five genera now listed ${ }^{2}$, with the exception of $N$ itrosocystis, seem never to have been observed again. In my opinion, fruiting bodies of Sorangium were mistaken for colonies of nitrifying bacteria, and were described in the three genera, Nitrosocystis, Nitrosogloe $a$ and Nitrocystis.

The descriptions and photomicrographs by $\mathrm{H}$. and $\mathrm{S}$. Winogradsky show that these genera are almost identical with one another. All three form large aggregates composed of numerous cysts. In some of the species, the cysts appear to be surrounded by a small sheath; but in every case they are composed of numerous, tightly packed, spherical or oval resting cells. This appearance is identical with that observed in Sorangium species.

Similarly, Winogradsky's photomicrographs of stained preparations of the disintegrated cysts of these genera closely resemble the appearance in Sorangium. Each shows the peculiar bean-shaped or wedge-shaped, capsulated structures arranged in pairs or tetrads, when stained by classical methods. My own cytological observations on Sorangium show, however, that this appearance is due to the fact that the microcyst wall is not readily stained. The micro. cysts actually contain a central vesicular nucleus, and are spherical or slightly oval in shape. Comparison of the photomicrographs of living and stained preparations of Nitrosogloea, for example ${ }^{3}$, show that this is also the case in the 'nitrifying' genera. The young cysts, photographed in situ, show tightly packed, spherical cells, which are not seen in the stained preparations.

The difficulties involved in obtaining pure cultures of nitrifying bacteria are well known. Although the inorganic medium prevents the growth of many micro-organisms, those Myxobacteria which are predatory on other bacteria could appear in the enrichment cultures. Examination for contaminants by the standard technique of inoculation into meat infusion broth fails to demonstrate their presence.

Winogradsky seems to have been unfamiliar with this group of the Myxobacteriales, because they are not mentioned in his soil studies ${ }^{1}$. The myxobacterial swarm is often difficult to detect, although the coloured fruiting bodies are visible to the naked eye.

Imsenecki has also suggested that Nitrosocystis is a species of Sorangium and has demonstrated that these Myxobacteria are common contaminants on cultures of nitrifying bacteria ${ }^{4}$.

Nitrosocystis has been regarded by some workers ${ }^{5,6}$ as a hard-colony variant of Nitrosomonas. In one instance ${ }^{5}$, there is no evidence that the cultures employed were pure, and in the other ${ }^{6}$ the brief description of the hard colonies in no way resembles the original descriptions of Nitrosocystis.

It would seem, therefore, to be almost certain that three of the genera of nitrifying bacteria now listed are invalid. They were, in fact, Myxobacteria of the genus Sorangium which were contaminating the cultures of Nitrosomonas.

Department of Bacteriology,

Joyce B. Grace

University of Birmingham. Feb. 27.

'Winogradsky, s., "Microbiologie du Sol" (Masson, Paris, 1949).

2 Bergey, "Manual of Determinative Bacteriology" (6th edit., 1948).

3 Winogradsky, H., Ann. Inst. Pasteur, 58, 333 (1937).

${ }^{4}$ Imsenecki, A., Nature, 157, 877 (1946).

' Kingma Boltjes, T. Y., Arch. f. Mikrobiol., 6, 79 (1935).

Hanks, R. H., and Weintraun, R. L., J. Bact., 32, 653 (1936)

\section{Microbiological Oxidation of Ammonium and Thiocyanate Ions in Soil}

Ammonium sulphate ${ }^{1}$ and sodium thiocyanate ${ }^{2}$, when perfused through chalked soils neutralized by calcium carbonate, are metabolized by the growth of specific groups of soil microflora on the soil crumb surface to nitrate and ammonium sulphate respectively.

Thiocyanate is a known inhibitor of bacterial growth and poison ${ }^{3,4}$ and is frequently found in sewage wastes. It has been reported to be highly toxic to the nitrification micro-organisms ${ }^{5}$. This inhibitory influence on the growth of the nitrifying micro-organisms in soil has been confirmed using the Audus modification ${ }^{8}$ of the original soil perfusion technique ${ }^{7}$. 